\title{
PENGEMBANGAN BAHAN PUSTAKA DAN INFORMASI
}

\section{Oleh: Dody Rusmono dan Santi Santika}

\begin{abstract}
Abstrak
Perpustakaan sekolah merupakan Pemenuhan kebutuhan para siswa sebagai Pemustaka pada perpustakaan sekolah memerlukan kehandalan Pustakawan sebagai pengelola utama aset intelektual perpustakaan. Koleksi yang berjumlah kurang dari 1000 judul dapat disiasati melalui kerjasama berjejaring antar perpustakaan sejenis. Idelanya, kedua sumber informasi berupa koleksi hard copy dan soft copy baik berupa buku maupun bukan-buku dapat dilayankan melalui system layanan perpustakaan hibrida. Kemasan demi kemasan informasi oleh Pustakawan sebaiknya dapat memberdayakan para siswa untuk memanfaatkan semaksimal mungkin kekayaan intelektual yang merupakan salah satu fasilitas sumber belajar. Tuga-tugas berupa PR Pekerjaan Rumah (take-home assignment oleh Guru diberikan sedemikian rupa sehingga secara tidak langsung mengharuskan para siswa memanfaatkan fasilitas yang disediakan di perpustakaan: memillih sendiri bahan, mengolahnya, dan menyajikan hasil pemikirannya dalam bentuk tulisan yang berbobot. Khusus untuk koleksi soft copy, alat telusur elektronik sangat membantu dan memperbaiki mutu perolehan bahan karena lebih mudah aksesnya, lebih akurat kontennya, dan biasanya lebih terkini dan lengkap. Sebagai intelektual muda yang merupakan harapan masa depan bangsa, para siswa perlu mendapat semacam Pendidikan Pemustaka agar pencarian berbagai sumber informasi menjadi lebih menyenangkan dan efektif.
\end{abstract}

Kata Kunci: bahan pustaka, sumber informasi

\section{A. Pendahuluan}

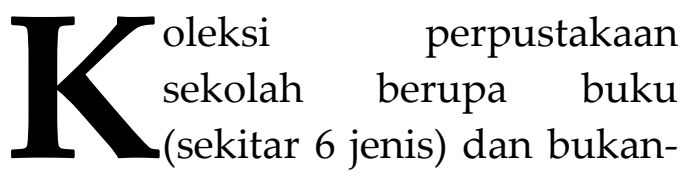
buku (sekitar 5 jenis) memerlukan penanganan Pustakawan handal agar didalam pengelolaannya koleksi itu dapat diberdayakan untuk dimanfaatkan sebesarbesarnya melalui akses oleh para Pemustaka.

Pengembangan bahan pustaka dan informasi perpustakaan sekolah bukan untuk menjadikan perpustakaan mengoleksi bahan secara lengkap melainkan untuk memenuhi kebutuhan. Tepatnya, jumlah koleksinya minimal-ideal: 10 buku per Siswa, dan minimal 60\% koleksi perpustakaan terdiri atas buku bukan-fiksi yang terkini (mutakhir) dan relevan dengan kurikulum.

Kehandalan Pustakawan sebagai pengelola utama koleksi mencakupi kegiatan pengadaan dan pengolahan, kemudian verifikasi koleksi (Stock Opname), dan akhirnya kegiatan pemeliharaan dan perawatan koleksi. Secara 
teknis, pemilihan bahan pustaka dan informasi perlu melalui tim seleksi, dan strategi penambahan koleksi harus selalu disesuaikan dengan keadaan serta kebutuhan (misalnya, permintaan para Siswa sebagai Pemustaka, perkembangan penerbitan, dan ketersediaan anggaran). Selain itu, pengolahan bahan harus akurat melalui katalogisasi dan klasifikasi, pemutakhiran katalog perlu secara rutin dilakukan, dan temperatur ruangan tempat koleksi dipajang perlu dijaga agar tidak panas dan tidak lembab. Belajar dari perawatan naskah kuno, koleksi sebaiknya ditempatkan didalam ruangan dengan suhu sekitar 15 derajat Celcius dengan tingkat kelembaban udara sekitar 45 derajat Celcius. Bila dimungkinkan, fumigasi dilakukan dengan menggunakan zat kimia untuk mencegah serangan serangga terhadap koleksi. Meskipun sebagian naskah koleksi sudah disimpan didalam media elektronik, wujud asli koleksi tetap harus ada karena peneliti sering masih memerlukan bentuk asli koleksi itu.

\section{B. Jenis Koleksi}

\section{Bahan Buku}

Dibandingkan dengan bahan bukan-buku, bahan buku lebih praktis, luwes, dan dapat dibawa kemana-mana. Bahan pustaka ini antara lain adalah buku teks, buku ajar, buku referensi, buku paket, majalah, dan koran.

\section{Bahan Bukan-Buku}

Ipteks (Ilmu Pengetahuan, Teknologi, dan Seni) memungkinkan koleksi bukan-buku dikelola dan dimanfaatkan oleh Pemustaka secara elektronik (digital) melalui alat telusur. Diantara koleksi jenis ini adalah mikrofis, microfilm, kaset, piringan hitam, dan CD ROM. Sedangkan alat telusurnya dapat berupa OPAC (Online Public Access Catalog).

\section{Pengadaan}

Karena koleksi merupakan nafasnya perpustakaan sekolah, hembusannya perlu dijaga agar tetap eksis: tidak tersengal-sengal, sesak, atau bahkan berhenti sama sekali. Pengadaan koleksi perpustakaan sekolah memerlukan beberapa pertimbangan. Diantaranya, yang dianggap penting adalah:

- Kebijakan Kepala Sekolah dengan mendengarkan saran para Guru, Komite Sekolah, Pustakawan, Siswa, dan Karyawan.

- Penetapan anggaran rutin ataupun bukan-rutin. Pengelolaan dana sekecil apapun akan berpengaruh terhadap pengembangan koleksi perpustakaan: pembelian buku, berlangganan majalah, surat 
kabar, dan terbitan berkala lainnya.

- Kerjasama dengan pihak lain seperti misalnya penerbit, LSM (Lembaga Swadaya Masyarakat), perpustakaan daerah, yayasan, dan organisasi keagamaan.

Sumber-sumber pengadaan bahan pustaka dan informasi perpustakaan sekolah adalah pembelian rutin, sumbangan, infak, titipan, tukar-menukar, dan pembuatan sendiri. Penambahan jumlah koleksi perpustakaan bisa dari pembelian yang perlu ditetapkan anggarannya yaitu sebesar $5 \%$ sampai $10 \%$ dari seluruh anggaran sekolah. Anggaran sebesar ini sebaiknya ditetapkan pada awal tahun dan disetujui oleh Komite Sekolah. Koleksi yang berasal dari sumbangan merupakan kreativitas Pustakawan untuk memperkenalkan diri dan mencari peluang memperoleh semacam atensi agar disumbang. Seorang Kepala Perpustakaan UPI pernah mengatakan bahwa Pustakawan adalah a beggar - a big one. Minta sana minta sini. Perolehannya dapat berupa buku atau majalah dari penerbit, perpustakaan daerah, pemerintah, masyarakat, pribadi, atau organisasi keagamaan. Tokohtokoh masyarakat, Guru, individu, atau siswa yang memiliki bahan pustaka berlebih tetapi tidak sempat membacanya karena kesibukan, dapat menjadi sumber sumbangan ataupun penitipan koleksi perpustakaan untuk dapat dilayankan dan dimanfaatkan oleh Siswa. Jenis koleksi "sementara" seperti ini tidak perlu diolah karena mungkin saja sewaktu-waktu diambil kembali oleh penitipnya. Sedangkan koleksi perpustakaan yang hampir tidak pernah diakses dan kurang relevan dengan visimisi-tujuan sekolah dapat ditukarkan ataupun dihibahkan ke sekolah ataupun lembaga pendidikan lainnya. Kreativitas Pustakawan menambah koleksi dapat berupa kliping, kompilasi makalah seminar/ workshop/ kongres/ symposium, bundel bahan ajar, atau bahkan pengumpulan bahan ujian untuk dikoleksi berupa Bank Soal.

Kegiatan pengadaan koleksi biasanya diawali dengan proses seleksi. Proses seleksi ini menggunakan alat bantu seperti katalog penerbit, bibliografi, OPAC, dan usulan dari komunitas sekolah. Proses seleksi dapat dilakukan secara manual dan elektronik.

Salah satu alat bantu seleksi secara elektronik adalah dengan menggunakan desiderata elektronik yaitu program yang memuat kumpulan daftar buku hasil seleksi yang akan diajukan dalam pemesanan buku untuk koleksi perpustakaan. 
Berikut ini adalah contoh digunakan di perpustakaan sekolah. desiderata elektronik yang dapat

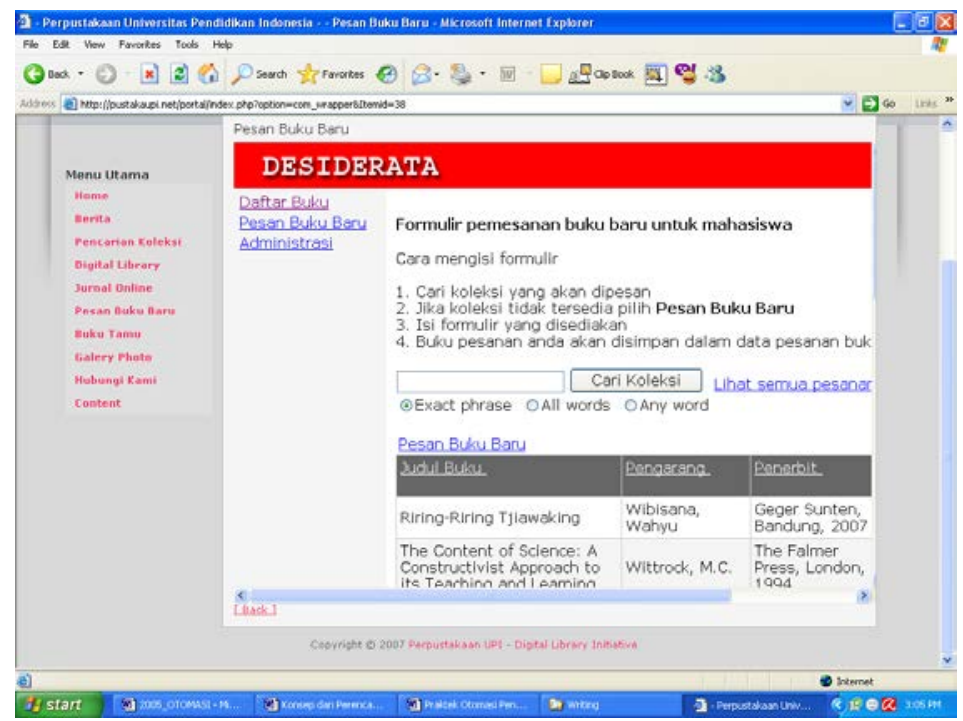

Gambar 1. Tampilan Daftar Buku pada Program On-line Desiderata

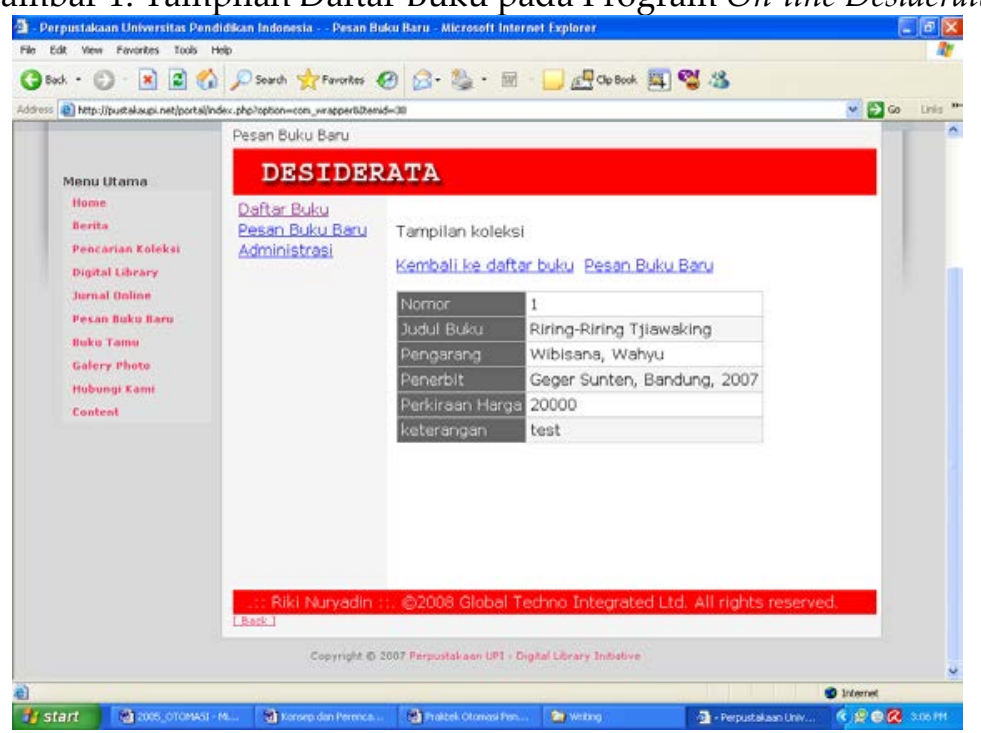

Gambar 2. Contoh tampilan koleksi pada On-line Desiderata 


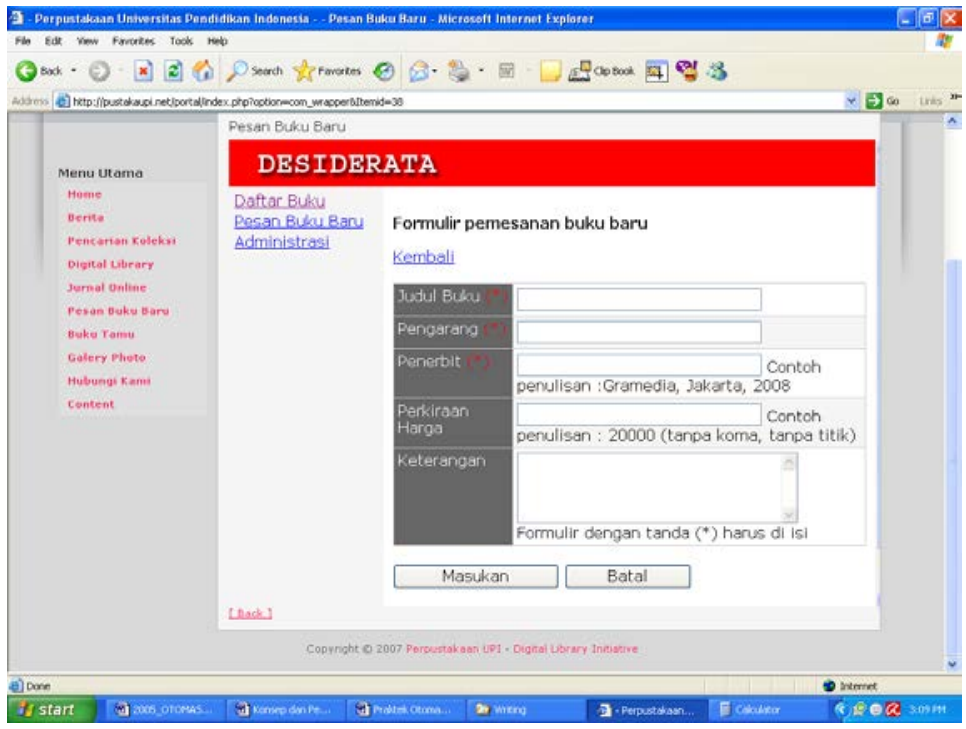

Gambar 3. Tampilan formulir pemesanan buku baru pada On-line Desiderata

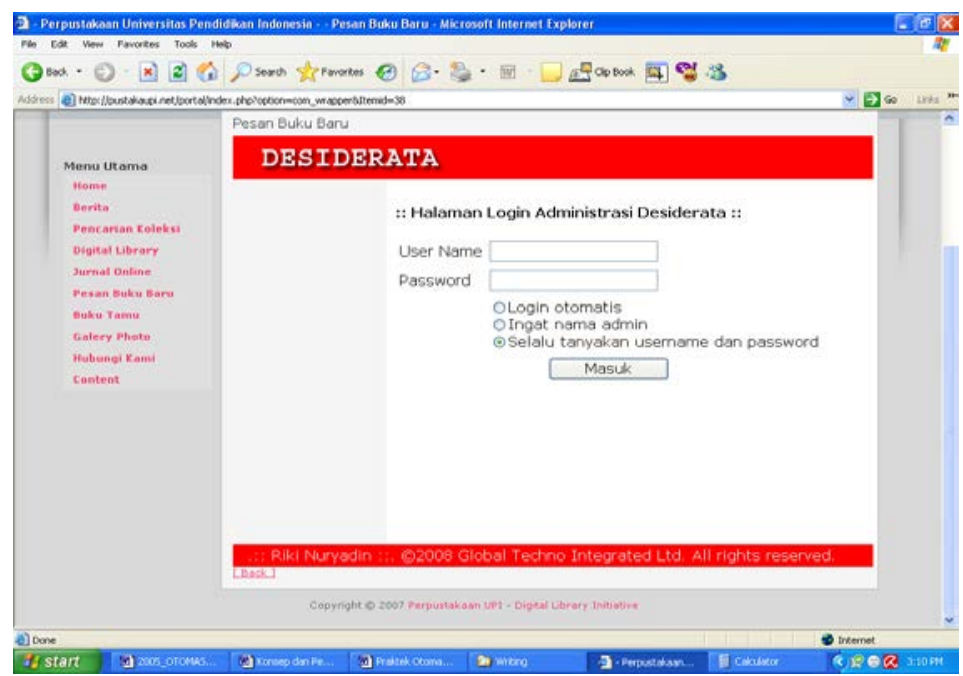

Gambar 4. Tampilan Login Administrasi On-line Desiderata

\section{Pengolahan}

Pengolahan bahan pustaka dan informasi mencakupi kegiatan pemberian tanda dan klasifikasi.

\section{Pemberian Tanda.}

Semua bahan pustaka yang diterima perpustakaan kecuali titipan, akan menjadi koleksi, dan oleh karenanya perlu diberi tanda pemilikan. Yang paling lazim adalah pemberian tanda berupa stempel. Peneraannya bisa dilakukan pada halaman judul di bagian dalam kertas sampul sedemikian rupa sehingga tidak memblokir tulisan judul dan tulisan lain yang merupakan data bibliografis. Agar mudah pengidentifikasiannya, stempel diterakan pada halaman per seratus misalnya 100, 200, 300, dan seterusnya. 
Stempel bisa berbentuk seperti dicontohkan berikut ini. bundar, segi tiga, atau segi empat,

\begin{tabular}{|l|}
\hline $\begin{array}{c}\text { Perpustakaan SD Makmur Jaya } \\
\text { Tanjungsari Tangerang }\end{array}$ \\
\hline Tanggal Terima \\
\hline Asal \\
\hline Sandi Pustaka \\
\hline No. Inventaris \\
\hline
\end{tabular}

Gambar 5. Stempel Inventarisasi

\begin{tabular}{|c|}
\hline MILIK \\
PERPUSTAKAAN \\
SMA Budi Mulia \\
Sragen \\
\hline
\end{tabular}

Gambar 6. Stempel Kepemilikan

\section{Klasifikasi.}

Untuk memudahkan temukembali, semua koleksi dikelompokkan menurut subyek/pokok masalah. Sistem pengelompokan menurut subyek ini beragam, antara lain DDC (Dewey Decimal Classification); UDC (Universal Decimal CLasification); LCC (Library of Congress Classification); BC (Bibliographic Calssification, CC (Colon Classification); dan Klasifikasi Islam. Banyak perpustakaan di Indonesia menggunakan sistem klasifikasi DDC (saat ini sudah terbit edisi ke 23). Untuk perpustakaan sekolah, klasifikasi persepuluhan dari Dewey (DDC) sudah cukup memadai. Sistem ini mengelompokkan koleksi berdasrkan subyek/pokok masalah dengan notasi angka persepuluhan. Pengelompokkan Kelas Utama yang terdiri dari 10 kelompok, akan dibagi lagi menjadi subyek yang lebih kecil yang disebut Divisi. Dari subyek yang kecil ini kemudian dibagi lagi menjadi subyek yang lebih kecil yang disebut SubDivisi, dan dari SubDivisi ini akan dibagi lagi menjadi pembagian yang lebih rinci.

Kelas Utama, terdiri dari 10 kelompok, adalah sebagai berikut: 000 - Karya umum 100 - Filsafat 200 - Agama 300 - Ilmu sosial 400 - Bahasa 500 - Ilmu pengetahuan murni 600 - Ilmu pengetahuan 
terapan/teknologi

700 - Seni, olahraga

800 - Kesusateraan

900 - Sejarah, geografi

Contoh subyek yang lebih kecil, Divisi, adalah seperti dibawah ini

400 - Bahasa

420 - Bahasa Inggris. Divisi ini akan diSubDivisikan menjadi, misalnya

421 - Sistem tulisan dan fonologi

422 - Etimologi bahasa Inggris

423 - Kamus bahasa Inggris

\section{E. Pencatatan}

Koleksi milik perpustakaan harus dicatat pada buku, kartu, atau sistem komputer. Kegiatan ini disebut juga Inventarisasi, yang memisahkan koleksi menurut jenis bahan informasi, misalnya buku, majalah, $C D$, film mikro, peta, dan gambar Arsitek. Inventaris untuk buku, misalnya memuat unsurunsur (kolom-kolom) seperti:
a. Nomor urut
b. Tanggal
c. Nomor inventaris
d. Asal
e. Pengarang
f. Judul
g. Impresum
h. Sandi pustaka

\begin{tabular}{|c|c|c|c|c|c|c|c|}
\hline $\begin{array}{c}\text { No. } \\
\text { Urut }\end{array}$ & Tanggal & No.Inv & Asal & Pengarang & Judul & Imprrsum & $\begin{array}{c}\text { Sandi } \\
\text { Pustaka }\end{array}$ \\
\hline & & & & & & & \\
\hline
\end{tabular}

Gambar 7. Contoh inventaris untuk buku (1)

\begin{tabular}{|c|c|c|c|c|c|c|c|c|c|c|c|c|c|c|c|c|c|}
\hline \multirow{2}{*}{$\begin{array}{l}\text { No. } \\
\text { Urut }\end{array}$} & \multirow[t]{2}{*}{ No.Inv } & \multirow[t]{2}{*}{ Tgl } & \multirow[t]{2}{*}{ Pengarang } & \multirow[t]{2}{*}{ Judul } & \multicolumn{5}{|c|}{ Asal Buku } & \multicolumn{4}{|c|}{ Bahasa } & \multicolumn{2}{|c|}{ Harga } & \multirow{2}{*}{$\frac{\text { No }}{\text { Klas }}$} & \multirow[t]{2}{*}{ Ket } \\
\hline & & & & & $\mathbf{W}$ & $\mathbf{H}$ & $\mathbf{P}$ & $\mathbf{L}$ & Dari & Ar & Ind & Ing & $\mathbf{L}$ & Sat. & $\mathrm{Jml}$ & & \\
\hline 1 & 2 & 3 & 4 & 5 & 6 & 7 & 8 & 9 & 10 & 11 & 12 & 3 & 14 & 15 & 16 & 7 & 18 \\
\hline
\end{tabular}

Gambar 8. Contoh inventaris untuk buku (2)

Pemberian nomor urut buku dapat diganti per tahun, misalnya nomor urut 10.000 pada pencatatan buku tahun berikutnya mulai dari 0 lagi dengan kode kelanjutan misalnya 0.1 yang berarti 10.001 . Dalam sistem inventarisasi ini satu eksemplar dibubuhi satu nomor. Jika satu judul mempunyai 4 eksemplar, maka nomor inventarisnya 4. Misalnya, $0.1,0.2$, 0.3 , dan 0.4 agar temu-kembali koleksi lebih mudah dan praktis. Pada kolom Tanggal diisi tanggal pencatatan pada buku inventaris, bukan tanggal penerimaan buku itu. Pada kolom Inventaris diisi nomor inventaris, diikutidengan 
asal buku dengan kode huruf tertentu, seperti misalnya:

\section{0/SMA/06 H}

Agar mudah untuk mengetahui bahwa bahan pustaka ini tercatat sebagai nomor 170 dari SMA (misalnya dari SMA Negeri V Cimahi) berupa hadiah (bukan dari pembelian ataupun tukarmenukar), dengan tanda H. Pada kolom Asal diisi nama orang, lembaga, organisasi atau yayasan yang memberi buku itu. Pada kolom Pengarang diisikan orang atas nama diri atau lembaga yang menciptakan karya itu, dan atas nama penanggungjawab karya itu. Nama pengarang ditulis tanpa pencantuman gelar akademik, gelar adat, pangkat militer ataupun gelar lainnya. Nama pengarang dituliskan berbalikan dengan urutan nama depan dan nama panjang agar selaras dengan sistem katalogisasi.

\section{Contoh:}

Nama pengarang asli lengkap Prof. Dr. Bambang Sudibyo, M.Sc. dituliskan Sudibyo, Bambang. Nama belakang (nama panjang) dahulu kemudian nama depan.

Judul buku hendaknya ditulis lengkap. Seandainya judul terlalu panjang, cukup dituliskan sebagian (depannya) dengan mernggunakan elipsis. Kata-kata yang dihilangkan itu diganti dengan tiga titik. Contoh:

Pelajaran bahasa Inggris untuk siswa-siswi terpilih dari SMP St. Michael Suku Jawa di Cimahi Jawa Barat. Judul sepanjang ini cukup dituliskan Pelajaran bahasa Inggris ...

Pada kolom Impresum atau imprint dituliskan nama kota terbit, nama penerbit, dan tahun terbit suatu buku. Contoh:

Bandung: Gramedia, 2010

Jika nama kota penerbitannya tidak diketahui, dituliskan ((s.l)) yang merupakan singkatan dari sino loco (tanpa lokal/tempat. Atau ((t.k)) yang merupakan singkatan tanpa kota. Apabila suatu buku mencantumkan lebih dari satu kota penerbitan, tuliskan satu saja yang disebutkan pertama. Contoh: 
Toronto, Tokyo, New York, Cimahi, Magetan: Pustaka Prima, 2011. Cukup dituliskan seperti ini:

Toronto: Pustaka Prima, 2011.

Sandi pustaka lebih populer dengan nama Call Number. Didalamnya terdapat antara lain nomor klasifikasi dan huruf depan judul buku.

Inventarisasi bahan pustaka dapat juga dilakukan secara elektronik. Inventarisasi bahan pustaka secara elektronik yaitu kegiatan pencatatan data koleksi yang dilakukan secara elektronik dengan bantuan media komputer. Langkah-langkah pencatatan pada inventarisasi bahan pustaka secara elektronik sama dengan langkahlangkah inventarisasi bahan pustaka secara manual. Perbedaannya terletak hanya pada proses pencatatannya.

Ada beberapa program yang dapat digunakan untuk inventarisasi bahan pustaka secara elektronik yang sederhana, diantaranya: MS Word, MS Excel, dan MS Access. Cara penggunaan program tersebut yaitu dengan membuat tabel inventaris seperti yang dirancang dalam inventarisasi secara manual, kemudian masingmasing kolom pada tabel tersebut diisi seperti pengisian secara manual. Di samping itu saat ini telah banyak program aplikasi komputer yang ditawarkan untuk inventarisasi bahan pustaka secara elektronik yang sekaligus dapat digunakan untuk katalogisasi, penelusuran, sirkulasi, dan pelaporan. Program-program aplikasi komputer tersebut diantaranya: CDS/ISIS, DYNIX, SIPISIS, dan sebagainya. Inventarisasi bahan pustaka menggunakan program aplikasi komputer tersebut yaitu data koleksi dimasukkan ke dalam lembar kerja yang ada pada program aplikasi komputer, kemudian data disimpan. Setelah data masuk, data dapat ditelusur dan ditampilkan sebagai katalog, atau dapat ditampilkan dalam bentuk tabel seperti buku induk, dan kemudian dapat dicetak.

Inventarisasi bahan pustaka secara elektronik memiliki kelebihan dalam penelusuran, yaitu penelusuran bahan pustaka dapat dilakukan secara lebih cepat, tepat, dan akurat. Di samping itu data bahan pustaka yang disimpan secara elektronik dapat disimpan dalam jumlah yang banyak dalam suatu basis data. 


\section{Contoh-contoh Kegiatan Unit Kerja Pengadaan yang telah terkomputerisasi}

\section{a. Komputerisasi Buku Induk dengan Program Excel}

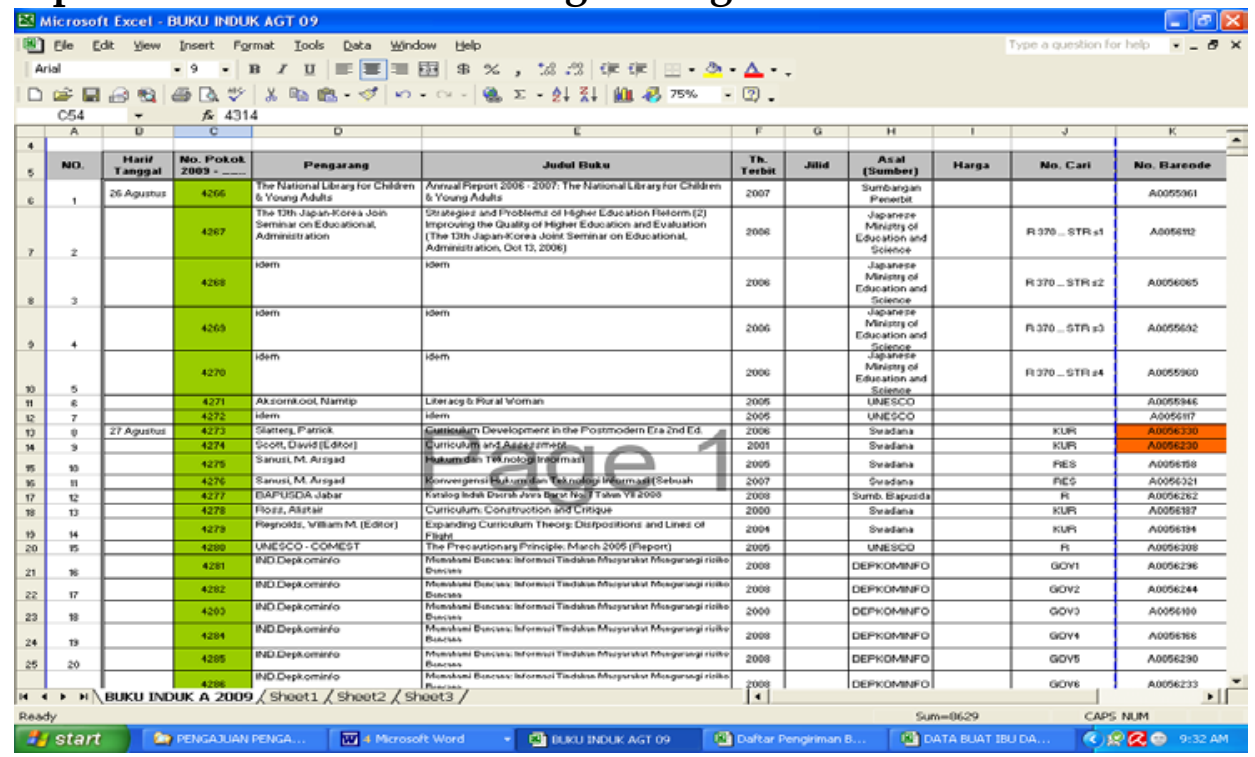

Gambar 9 Tampilan Gambar Buku Induk

\section{b. Daftar Pengiriman Buku Ke Pengolahan}

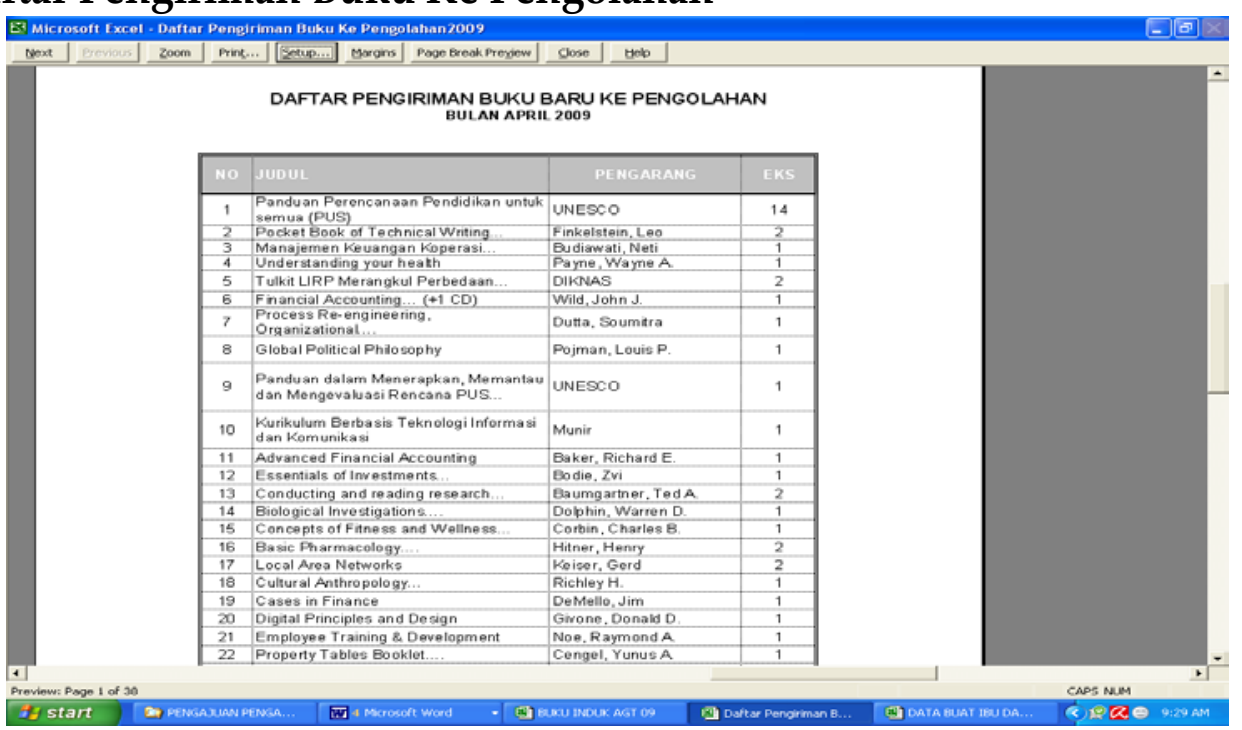

Gambar 10 Tampilan Daftar Pengiriman Buku Baru ke Pengolahan 


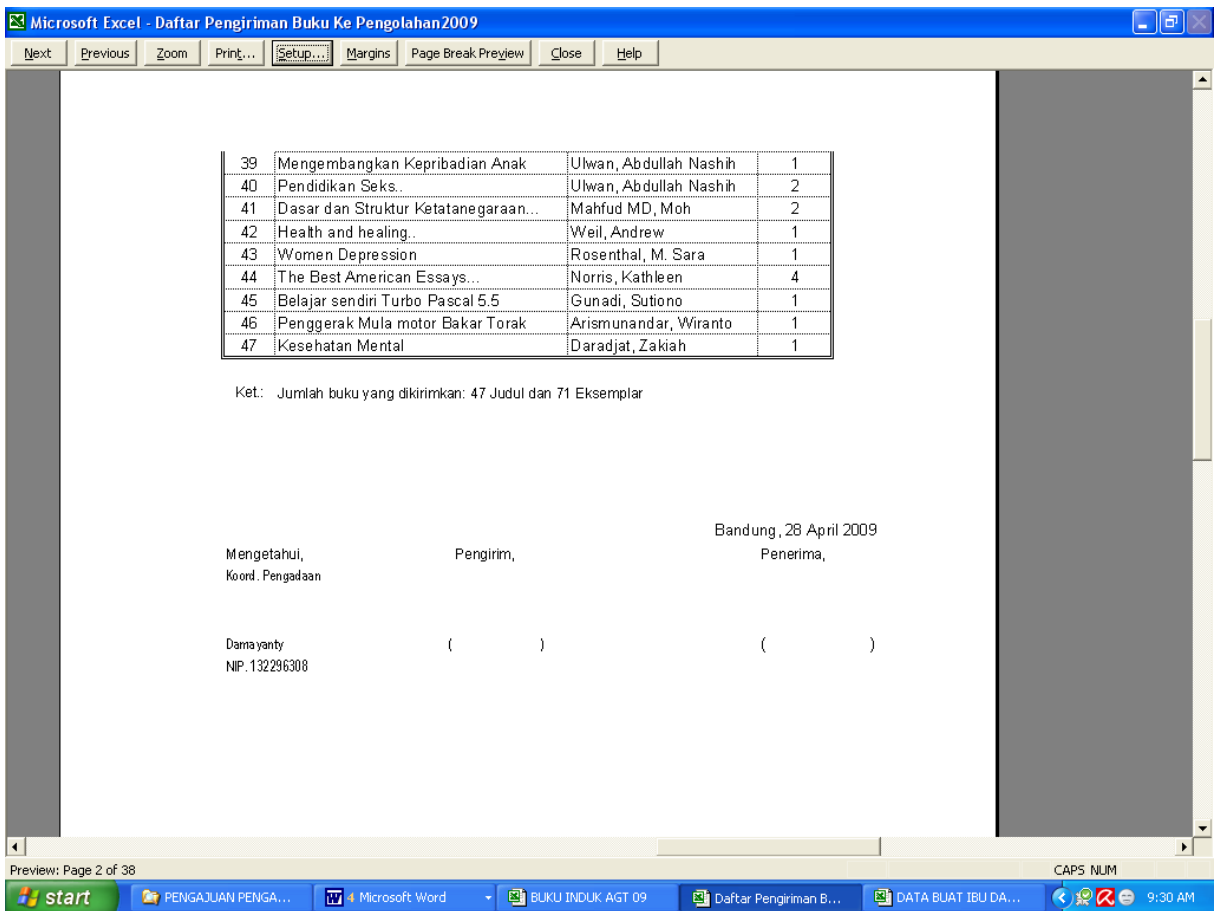

Gambar 11 Tampilan Daftar Pengiriman Buku Baru ke Pengolahan (Halaman akhir)

\section{c. Daftar Pengajuan Koleksi Perpustakaan}

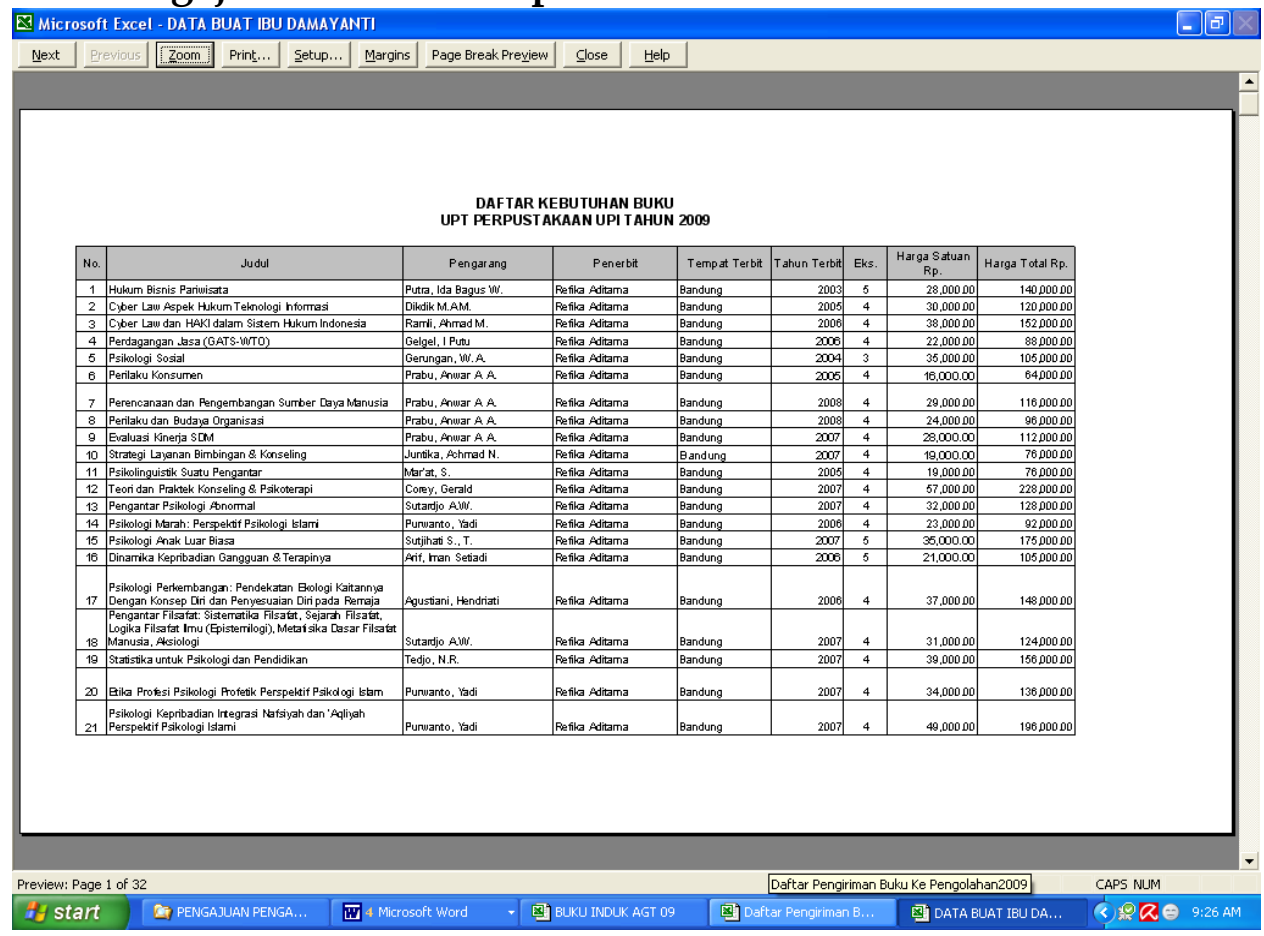

Gambar 12 Tampilan Daftar Pengajuan Kebutuhan Buku Baru Perpustakaan 


\section{F. Pengkatalogan}

Lazim juga disebut katalogisasi, dengan pelaksana kegiatannya disebut kataloger. Pengkatalogan ini adalah proses pembuatan daftar pustaka dan informasi (misalnya: buku, majalah, CD, film mikro) milik perpustakaan. Daftar ini berfungsi untuk mencatat koleksi yang ada untuk membantu proses temukembali, dan untuk mengembangkan standar-standar bibliografi internasional. Daftar ini bisa dibuat dalam bentuk katalog cetakan, katalog berkas, catalog kartu, maupun dalam bentuk perangkat lunak (software) yang lazim disebut OPAC. Masingmasing bentuk katalog ini

mempunyai kelebihan dan kekurangannya. Fungsi katalog, diantaranya adalah:

- Sebagai inventaris koleksi yang ada di perpustakaan

- Memberikan kemudahan kepada Pemustaka yang hanya mengetahui pengaang, judul, atau subyeknya saja untuk menemukan bahan pustaka

- Memberikan deskripsi singkat kandungan bahan pustaka, terutama buku

- Sebagai alat bantu untuk mencari lokasi bahan pustaka yang disusun di rak.

Penyusunan catalog Pengarang disusun secara alfabetis, seperti contoh di bawah ini.

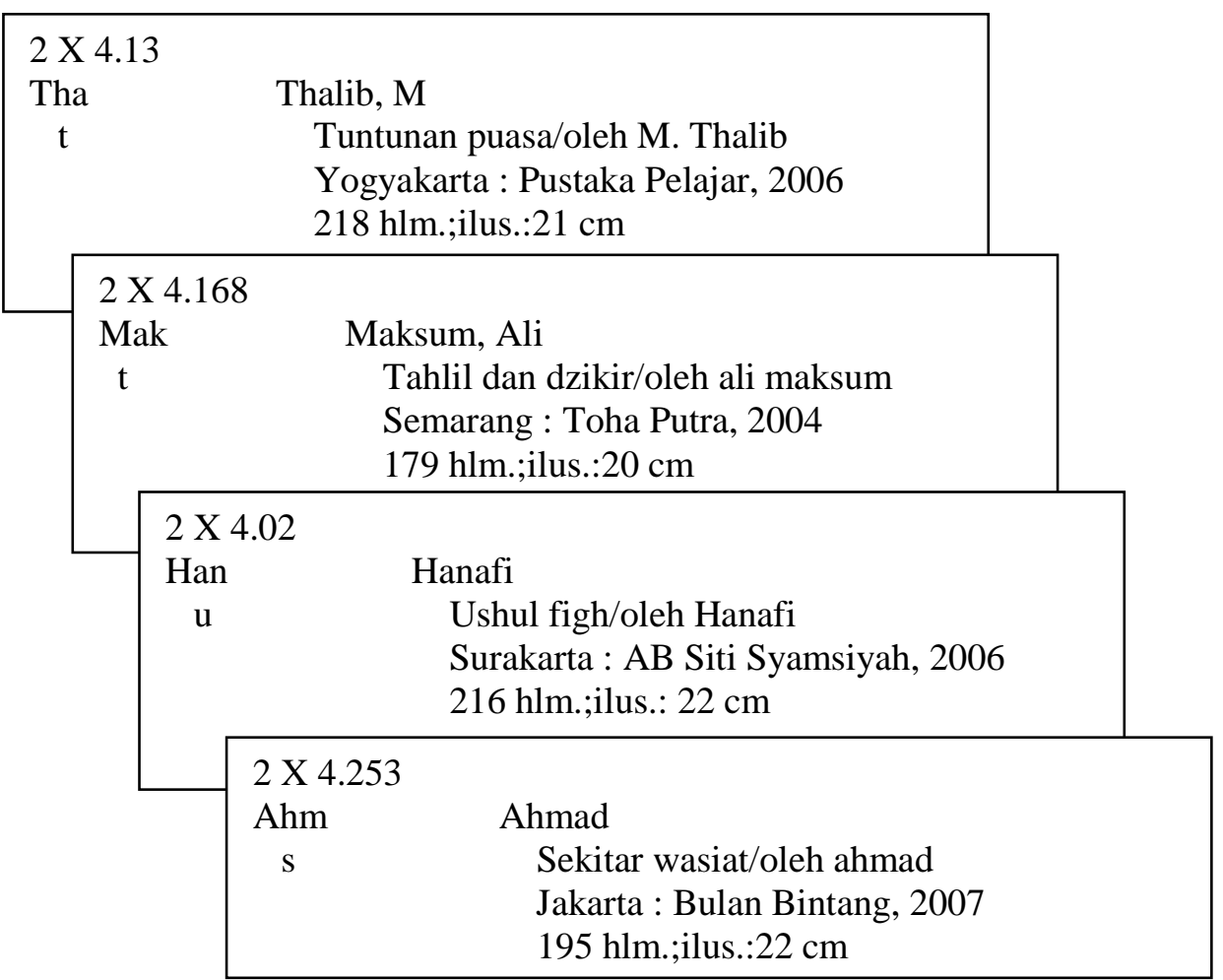

Gambar 13. Penyusunan katalog pengarang secara alfabetis 
Pembuatan katalog/daftar pengarang (kepengarangan), edisi, koleksi perpustakaan harus imprint, kolasi, seri, catatan/notasi, mengikuti pedoman, seperti dan ISBN (International Serial Book misalnya AACR (Anglo-American Number). Misalnya, area judul dan Cataloguing Rules) atau, Pedoman pengarang terdiri dari judul Katalogisasi Indonesia terbitan sebenarnya, judul paralel, anak Perpusnas RI (Perpustakaan judul, dan pernyataan Nasional Republik Indonesia). kepengarangan. Tentang Katalogisasi koleksi mencantumkan daerah/area deskripsi atau uraian, yang terdiri dari: daerah judul dan

pengarang, misalnya, ada beberapa jenis, seperti berikut ini:

1. Pengarang Tunggal. Apabila terdapat monograf, buku, maupun kumpulan tulisan satgu orang, maka tajuknya adalah Pengarang.

Contoh:

Judul buku: Belajar Membaca Al-Qur'an

Pengarang: Abdullah Hasan

maka tajuknya adalah Hasan, Abdullah

2. Anonim. Apabila suatu karya atau karangan tidak diketahui samasekali nama pengarangnya, atau, pengarangnya menggunakan tanda-tanda tertentu/inisial sebagai pengganti nama aslinya. STA, misalnya adalah kependekan dari Sutan Takdir Alisyahbana. Apabila terdapat karya tulis anonim, maka tajuknya dibuat dengan Judul.

Contoh:

Judul buku: Layar Terkembang

Penarang: STA

Tajuk: Layar Terkembang

3. Pengarang Ganda. Apabila ada buku atau karya lain dengan pengarang lebih dari seorang, maka tajuknya ditentukan pada Pengarang yang pertama kali disebut. Untuk Pengarang kedua, ketiga, dan selanjutnya, dibuatkan tajuk tambahan. Contoh:

Judul karya: Sejarah Indonesia

Para Pengarang: Kuntowijoyo, Sartono, Adaby

Tajuk: Kuntowijoyo 
4. Editor. Pengumpul naskah/karya sendiri atau orang lain lalu diedit/disusun dan diterbitkan. Kadang-kadang editor tidak sendirian dalam mengerjakan tugasnya, karena dibantu oleh orangorang lain. Apabila ada karya editor, maka tajuknya ditentukan pada Editor.

Contoh:

Judul karya: Kepemimpinan Islam

Para Editor: Amien Rais, Abdul Minir Mulkan, Rosyad Saleh.

Tajuk: Rais, Amien

5. Pengumpul. Seseorang atau beberapa orang yang mengumpulkan karya-karya tulis orang lain dalam suatu pokok masalah atau lebih, pencantuman tajuknya ditentukan pada Editor. Contoh:

Judul karya: 1) Fiqh Taharah; 2) Fiqh Shalat; 3) Fiqh Puasa

Para Pengarang: 1) Marzuki Rasyid; 2) Ismail Thaib; 3) Husein Yusuf

Ketika ketiga karya dengan tiga orang Pengarang itu dikumpulkan oleh Amir Mualim lalu diterbitkan dengan judul Figh Ibadah, maka penulisan tajuknya pada Pengumpul, yaitu Amir Mualim, dan dituliskan sebagai berikut:

Tajuk: Mualim, Amir.

6. Pengarang Badan Korporasi. Suatu karya yang disusun oleh badan korporasi seperti misalnya nama lembaga, yayasan, instansi pemerintah, persyarikatan, organisasi nasional maupun badan internasional, tajuknya ditentukan pada badan korporasi itu karena badan itu yang bertangung jawab atas substansi karya. Contoh karya seperti ini adalah:

- Laporan yang disusun dan diterbitkan atas nama badan

- Perundang-undangan, peraturan, laporan pertanggungjawaban lembaga

- Karya-karya yang diterbitkan oleh badan korporasi yang bukan penerbit professional dengan catatan bahwa dalam karya itu tidak terdapat nama Pengarang maupun Pengumpul. 
Contoh:

Judul karya: Laporan Tahunan Rektor UPI

Tajuk: Universitas Pendidikan Indonesia

Penentuan tajuk terdiri dari dua, yaitu tajuk entri utama, dan tajuk entri tambahan. Tajuk entri utama adalah nama, kata, atau gabungan kata yang ditulis pada bagian atas tiap kartu katalog yang menunjukkan aspek dari buku, pengarang, judul subyek dari isi buku, dan seri. Tajuk entri tambahan adalah tajuk entri yang merupakan tambahan pada tajuk entri utama dalam katalog. Peraturan tajuk entri tambahan ini memperbesar kemungkinan pendekatan untuk mendapatkan suatu karya disamping melalui tajuk entri utama.
Katalogisasi terbitan berkala seperti misalnya surat kabar, majalah, jurnal, buletin, newsletter, yang dimiliki perpustakaan harus dibuatkan katalognya agar memudahkan proses temu-kembali. Katalognya dapat dibuat dalam bentuk cetak, kartu, atau software tertentu. Unsur-unsur yang harus dicantumkan didalam katalog adalah: judul, penanggung jawab, nomor pertama, frekuensi terbit, nama lembaga yang menerbitkan, tahun, bulan, volume, nomor majalah yang dimiliki perpustakaan, edisi, penomoran, dan deskripsi fisik. Contoh:

Analisis Pendidikan/Kementrian Pendidikan Nasional.

Vol.I No.1, 2009.

Jakarta: Kemendiknas, 2007 - 2010

Ilus.,

ISSN

Triwulan

Perpustakaan memiliki:

Tahun

2006

2007

dst.

Katalogisasi bahan bukankertas pada dasarnya menampilkan data fisik koleksi tersebut. Unsur-
Volume

Nomor

I

$1,2,3,4$

II

$1,2,3,4$

unsur yang perlu dicantumkan adalah:

a. Nomor klasifikasi 

b. Jenis bahan (Film, CD, Kaset, Slide, Mikrofis)
c. Nama penanggung jawab, pencipta lagu, sutradara, penceramah, penyusun, dan lain-lain
e. Edisi, tahun, hak cipta, tahun beredar, dll.
f. Kolasi (berisi jumlah kaset, piringan hitam)
g. Jejakan
h. Catatan lain
d. Sponsor, agen, perusahaan, dsb.

Contoh-contoh kartu katalog bahan non kertas:

1. Film

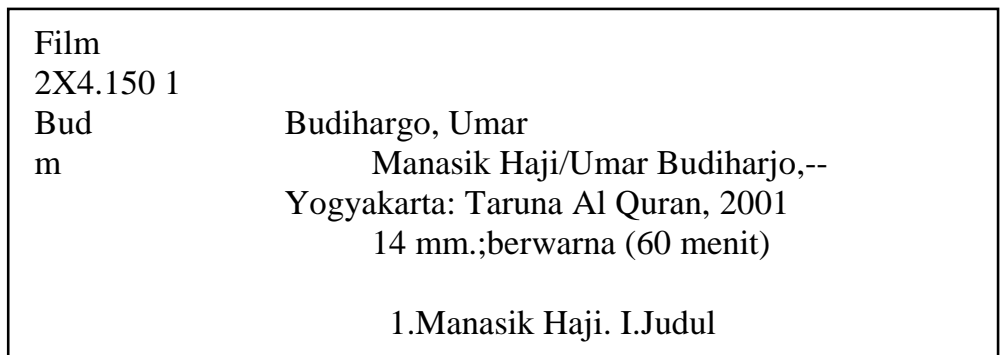

\section{Kaset}

$\begin{array}{ll}\text { Kaset } & \\ \text { 2X0 } & \\ \text { Fac } & \text { Fachruddin, A.R. } \\ \mathrm{t} & \text { Tanya Jawab Agama Islam/A.R. } \\ & \text { Fachruddin; Muchlas } \\ & \text { Abror.-Yogyakarta: Majelis Tabligh } \\ & \text { PP. Muhammadiyah, 1994. } \\ & 6 \text { kaset (60 menit) } \\ & \text { 1.Islam. I.A.R. Fachruddin } \quad \text { II.Judul }\end{array}$

\section{Slaid (slide)}

$\begin{array}{lc}\text { Slaid } \\ \text { 2X4.12 } \\ \begin{array}{ll}\text { Asy } \\ \mathrm{m}\end{array} & \begin{array}{l}\text { Asyumuni A.R. } \\ \text { Cara Sholat/ Asyumuni A.R.,--Yogyakarta: }\end{array} \\ & \text { Al Hidayah, 1996 } \\ & 50 \text { slaid; berwarna,5X5 cm dan } 5 \text { Kaset } \\ & \text { (30 menit) } \\ & \text { 1.Sholat I.Asymuni A.R. II. Judul }\end{array}$




\section{Kaset Video}

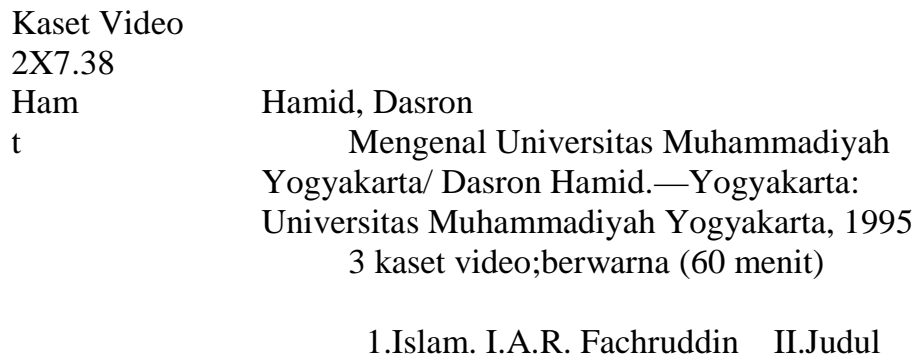

Sesuai dengan perkembangan TIK \{Teknologi Informasi dan Komunikasi $=$ ICT (Information and Communication Technology)\} dan untuk efisiensi maupun efektivitas, sangat dianjurkan bahwa katalog perpustakan sekolah dikemas dalam bentuk software terrtentu seperti CDS/ISIS, NCI Bookman, dsb. Katalog elektronik ini disebut OPAC.

\section{G. Pelabelan}

Pelabelan (labeling) adalah proses pembuatan kartu buku, etiket buku, lembar kembali, dan kantong buku.

a. Etiket buku dibuat dari kertas HVS berukuran 1/16 folio sebagai tempat penulisan sandi pustaka. Kertas ini ditempelkan pada punggung buku kira-kira $5 \mathrm{~cm}$ dari bawah.

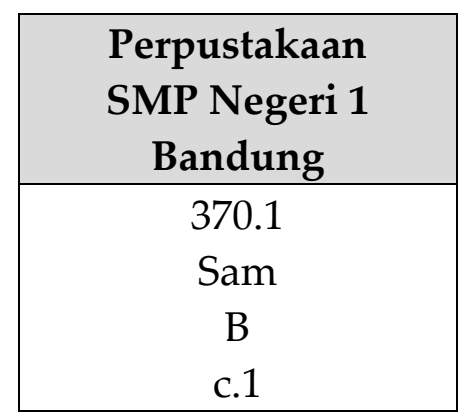

Gambar 14. Label Buku

b. Lembar tanggal kembali dibuat dari kertas HVS berukuran $1 / 4$ folio atau 10,5X17 cm. Pada lembar ini dituliskan nomor/nama anggota dan tanggal wajib pengembalian. 


\begin{tabular}{|l|l|}
\hline \multicolumn{2}{|c|}{ Perpustakaan } \\
SMP Negeri 5 Bandung \\
\hline Nomor/nama anggota & Tanggal wajib kembali \\
\hline & \\
\hline & \\
\hline & \\
\hline
\end{tabular}

Gambar 15. Lembar Tanggal Kembali

c. Kartu buku berukuran 1/4 folio, dibuat dari kertas manila berwarna atau kertas putih. Kartu ini berisi nomor inventaris, nama Pengarang buku, judul buku, sandi pustaka, dan tanggal pengembalian.

\begin{tabular}{|l|l|}
\hline \multicolumn{2}{|c|}{ SDN Merpustakaan } \\
\hline Kartu Buku \\
No. Invent : \\
Pengarang : \\
Judul buku : \\
\hline No. Anggota & Tanggal Pinjam \\
\hline & \\
\hline & \\
\hline & \\
\hline
\end{tabular}

Gambar 16. Kartu Buku

d. Kantung buku dibuat dari kertas HVS dalam bentuk segitiga ataupun segi empat yang berfungsi sebagai tempat kartu buku dan ditulisi sandi pustaka maupun nomor inventaris.

\section{H. Penjajaran}

Buku-buku yang sudah selesai proses pengolahannya, kemudian dipilah jenisnya: buku teks, buku referensi, atau jenis lain. Pemajangan buku dilakukan sedemikian rupa sehingga mudah dikenali

Pemustaka (pengunjung/Siswa). Siswa harus dibuat tertarik untuk memanfaatkan koleksi perpustakaan, terutama buku-buku baru. Pemajangan buku referensi (buku yang hanya memberikan informasi singkat tentang bahasa, peristiwa, nama orang, alamat, lokasi, nomor, dan lainnya). Penjajarannya di rak dapat dipilih diantara dua sistem, yaitu: 
1. Berdasarkan jenis. Koleksi yang terdiri dari kamus, ensiklopedia, manual, buku tahunan, sumber-sumber bibliografi, indeks, dan abstrak itu disusun berdasarkan jenisnya. Dalam hal ini semua kamus dalam bidang apapun dijadikan satu susunan.

2. Berdasarkan sandi pustaka. Cara penyusunan ini sama dengan cara penyusunan buku teks, yaitu disusun berdasarkan urutan nomor kelas sesuai dengan peraturan tata susunan koleksi.

Penjajaran buku teks dilakukan berdasarkan sandi

Contoh:

$\begin{array}{lll}001.5 & 001.52 & 137.98 \\ \text { Asd } & \text { Mut } & \text { Abr } \\ \text { a } & \text { v } & \text { i }\end{array}$

Dalam penjajaran buku, perlu diperhatikan hal-hal sebagai berikut:

a. rak buku tidak diisi penuh untuk memudahkan penambahan dan penggeseran

b. digunakan standar buku

c. buku tidak disusun berlapis/ditumpuk

d. rak hendaknya mudah dipindahkan pustaka (call number) atau nomor punggung buku dengan cara penyusunan sebagai berikut:

a. dimulai dari angka decimal kecil ke decimal besar pada sandi pustaka yang ditempelkan pada masingmasing punggung buku.

b. penyusunan dari kiri ke kanan dalam satu kotak lemari, dari atas ke bawah.

c. diikuti pengurutan huruf pertama judul buku yang disusun secara alfabetis, kemudian diurutkan jilid, bagian, dan eklsemplar.

e. desain rak disesuaikan agar terjadi sirkulasi udara yang baik

\section{Pengawetan dan Pelestarian}

Nilai informasi bahan pustaka dan informasi perlu dilestarikan agar dapat dimanfaatkan sepenjang masa. Salah satu caranya adalah memahami faktor-faktor penyebab kerusakan bahan pustaka dan informasi, yaitu faktor biologi, 
fisika, dan kimiawi. Faktor biologi mencakupi serangga, lumut, dan jamur. Faktor fisika meliputi cahaya, panas, dan uap air. Ketiga faktor ini menyebabkan terjadinya reaksi fotokimia, hidrolisa, atau oksidasi didalam kertas.

Tujuan pemeliharaan bahan pustaka adalah agar kandungan informasinya lebih awet, penyebarannya lebih luas, dan pengembangan-lanjutnya lebih membuka cakrawala. Pelestarian bahan pustaka ini dapat dilakukan dengan cara reproduksi, penjilidan, laminasi/penyampulan, dan fumigasi. Diantara yang paling jarang untuk dilaksanakan karena satu dan lain alasan, adalah penyiangan (weeding). Penyianan adalah proses mengeluarkan buku dari jajaran koleksi. Pertimbangannya adalah bahwa koleksi itu sudah tidak diminati oleh pemustaka, sudah ada edisi terbarunya, atau bertentangan dengan kebijakan pemerintah dan etika masyarakat.

Pemeliharaan bahan bukankertas, misalnya film. Jenis koleksi ini memerlukan perawatan yang hati-hati. Pada umumnya informasi yang terkandung didalamnya memiliki nilai tinggi yang perlu dilestarikan. Daya tahan jenis dokumen ini ditentukan oleh kestabilan kimiawi bahan itu sendiri, pemrosesannya, kondisi tempat penyimpanannya, perawatannya,

dan penggunaannya. Untuk mencapai hasil maksimal, suatu model organisasi perawatan bahan pustaka dapat dirujuk. Secara rinci langkah dan mekanisme kerjanya ditetapkan. Namun demikian, pelestarian bahan pustaka di Indonesia masih terkendala oleh beberapa faktor, seperti:

- Kurangnya tenaga pelestari dan belum jelas apakah pelestarian dilakukan oleh tenaga teknisi ataukah harus tenaga tingkat professional.

- Kurangnya perhatian dan fasilitas yang tersedia yang diberikan oleh pembuat kebijakan.

- Praktik pelestarian yang selama ini dilakukan masih keliru.

- Jenis dan kualitas kertas bahan pustaka yang beraneka ragam, dari yang rendah sampai yang tinggi.

- Tidak adanya ruangan khusus yang dirancangbangun sesuai dengan keperluan pelestarian.

- Tidak adanya kebijakan pelestarian nasional yang dapat dirujuk, termasuk kebijakan pelestarian koleksi digital.

\section{J. Penutup}

Materi yang dipilih untuk koleksi perpustakaan sekolah seyogiyanya merupakan hasil 
kolaborasi antara Kepala Sekolah, Guru, Pustakawan, dan Siswa. Idealnya, koleksi perpuastakaan dapat mencerminkan minat dan budaya Siswa tanpa melewati batas wajar standar etika. Electronic resources yang beragam harus mencerminkan kurikulum dan minat serta budaya siswa sebagai pemustaka. Gangguan fisik dan gangguan biologis yang dialami koleksi harus teramati secara dini agar tindakan pencegahan untuk melestarikannya tidak terlambat.

\section{K. Daftar Pustaka}

Heery, Mike and Steve Morgan. 1996. Practical Strategies for the
Modern Academic Library.

London: Aslib.

Hs, Lasa. 2007. Manajemen Perpustakaan Sekolah. Yogyakarta: Pinus Book Publisher.

Ns, Sutarno. 2004. Manajemen Perpustakaan: suatu pendekatan praktik. Jakarta: Samitra Media Utama.

Suherman. 2009. Perpustakaan Sebagai Jantung Sekolah: referensi pengelolaan perpustakaan sekolah. Bandung: MQS Publishing.

Yulia, Yuyu dan Janti G.S. 2009. Pengembangan Koleksi. Cetakan ke 6. Jakarta: Universitas Terbuka. 


\section{"Setiap warga negara berhak mendapat pendidikan."}

\section{Pasal 31}

Undang-undang Dasar Negara Republik Indonesia tahun 1945 